\title{
Tidal generation of large sub-mesoscale eddy dipoles
}

\author{
W. Callendar ${ }^{1}$, J. M. Klymak ${ }^{2}$, and M. G. G. Foreman ${ }^{1}$ \\ ${ }^{1}$ Institute of Ocean Sciences, Fisheries and Oceans Canada, Sidney B.C., Canada \\ ${ }^{2}$ School of Earth and Ocean Sciences, and Dept. of Physics and Astronomy, University of Victoria, B.C., Canada
}

Received: 26 February 2011 - Published in Ocean Sci. Discuss.: 7 April 2011

Revised: 6 July 2011 - Accepted: 20 July 2011 - Published: 3 August 2011

\begin{abstract}
Numerical simulations of tidal flow past Cape St. James on the south tip of Haida Gwaii (Queen Charlotte Islands) are presented that indicate mesoscale dipoles are formed from coalescing tidal eddies. Observations in this region demonstrate robust eddy generation at the Cape, with the primary process being flow separation of buoyant or wind driven outflows forming large anti-cyclonic, negative potential vorticity, Haida Eddies. However, there are other times where dipoles are observed in satellites, indicating a source of positive potential vorticity must also be present. The simulations here build on previous work that implicates oscillating tidal flow past the cape in creating the positive vorticity. Small headland eddies of alternating vorticity are created each tide. During certain tidal cycles, the headland eddies coalesce and self organize in such a way as to create large $>20-\mathrm{km}$ diameter eddies that then self-advect into deep water. The self advection speed is faster than the beta drift of anti-cyclones, and the propagation direction appears to be more southerly than typical Haida Eddies, though the model contains no mean wind-driven flows. These eddies are smaller than Haida Eddies, but given their tidal origin, may represent a more consistent source of coastal water that is injected into the interior of the subpolar gyre.
\end{abstract}

\section{Introduction}

Eddies are an important mechanism for stirring the ocean and transporting nutrients and other tracers long distances. For example, Haida eddies generated at the south tip of Haida Gwaii (Queen Charlotte Islands) each transport 3000 to $6000 \mathrm{~km}^{3}$ of coastal water into the Gulf of Alaska, carrying nutrients up to $1000 \mathrm{~km}$ and persisting for several years

Correspondence to: J. M. Klymak (jklymak@uvic.ca)
(Whitney and Robert, 2002). The westward flux of salt in Meddies has been estimated at $3 \times 10^{5} \mathrm{psu} \mathrm{m}^{3} \mathrm{~s}^{-1}$ (Wang and Dewar, 2003), leading to the supposition that Meddies are likely a significant part of the westward salinity flux in the Mediterranean water salt tongue (McWilliams, 1985).

The vorticity that causes eddies may be generated in three ways: (i) through baroclinic or other flow instability, (ii) via a mixing event followed by geostrophic adjustment, or (iii) through friction and flow separation. Baroclinic instability requires strong geostrophic currents, such as the Gulf Stream (Gill, 1982). While the formation of Sitka eddies at the Alaskan Panhandle has been attributed to baroclinic instability (Melsom et al., 1999; Thomson and Gower, 1998), the current responsible for this instability is wind-driven. In our work in this paper, we do not have wind forcing or mean baroclinic gradients in our models, so baroclinic instability is not a process we address. Similarly, eddies can also result from unsteady vortex stretching of planetary vorticity, believed to be important in density-driven overflows (i.e. Bruce, 1995; Lane-Serff and Baines, 1998; Cenedese et al., 2004). This process is not likely important for the present situation.

The second generation mechanism, geostrophic adjustment of mixed water, was hypothesized by McWilliams (1985) to be the cause of submesoscale coherent vortex (SCV) formation. SCVs have horizontal scales not greater than the first baroclinic radius of deformation, have a predominantly anti-cyclonic rotation, and are found throughout the world's oceans. The rotation requires them to have a generation mechanism which produces a rotational bias such as would be found in the gravitational collapse of recently mixed fluid (Sundermeyer and Ledwell, 2001).

D'Asaro (1988) explored the final method, friction and flow separation, while investigating submesoscale eddies in the Beaufort Sea. While these eddies fit the description for SCVs, he argued that they could not have been generated through mixing. For a homogeneous system, as would be

Published by Copernicus Publications on behalf of the European Geosciences Union. 
produced by a mixing event, the appropriate expression for potential vorticity (PV) is (Gill, 1982):

$q=\frac{\zeta+f}{H}$

where $\zeta$ and $f$ are the relative and planetary vorticity respectively and $H$ the depth of the mixed region. In the case of these particular eddies, the depth of the mixed region required to produce the observed change was unreasonably large, exceeding the total depth of the generation region. D'Asaro (1988) proposed instead that the vorticity was produced via bottom friction. In his observations, flow passes through a canyon, intensified on the right-hand side of the canyon by the Coriolis force, generating negative vorticity on the wall. At the end of the canyon, the coast veers sharply, causing the flow to separate and the negative vorticity in the water is manifested as anti-cyclonic eddies.

Tidal flow across a cape may generate eddies in much the same way (Signell and Geyer, 1991; Klymak and Gregg, 2001; MacCready and Pawlak, 2001). However, rather than generating a continuous stream of eddies rotating the same way, oscillating tides generate eddies which rotate in alternating directions. The formation and behaviour of these eddies can be predicted based on the values of two parameters: a frictional Reynolds number $R e_{\mathrm{f}}=H / C_{\mathrm{d}} a$ and the Keulegan-Carpenter number $K_{c}=T U / a$ (Signell and Geyer, 1991). The first expresses the relative importance of advection and bottom friction: where $H$ is the water depth away from the cape, $C_{\mathrm{d}}$ is the drag coefficient and $a$ the headland length (alongshore extent). The second parameter, $K_{c}$, quantifies the importance of advection to local acceleration, where $T$ is the period of the oscillating flow, $U$ the mean advection speed and $a$ the width of the obstacle. For the case $K_{c}<R e_{\mathrm{f}}$, an eddy will be formed on each half-cycle of the tide. Friction is weak enough that an eddy lasts to interact with the eddy generated on the successive tide and the two eddies form a dipole and self-advect away from the cape.

To generate an eddy at all, there must be separation of the boundary layer from the cape (Kundu, 1990); separation will occur if the radius of curvature of the cape is less than $H / C_{\mathrm{d}}$ where $H$ is the constant water depth away from an initial slope at the coastline and $C_{\mathrm{d}}$ a bottom friction coefficient (Garrett, 1995). So, for a depth $H$ of $50 \mathrm{~m}$ and $C_{\mathrm{d}} \approx 1 \times 10^{-3}$, separation will occur if the radius of curvature for the cape is $50 \mathrm{~km}$ or less.

In this study, we are interested in eddy dipoles generated at Cape St. James. There have been other studies of eddy generation at this cape, most notably to look at generation of Haida eddies. Haida eddies are large negative PV anomalies formed in the wintertime, and are responsible for the transport of nutrient-rich coastal water into the Gulf of Alaska (Whitney and Robert, 2002). Crawford et al. (2002) hypothesized that these eddies were generated due to northward winter winds piling surface water in Hecate Strait. The southward return flow was concentrated to the west side of the strait due to the
Coriolis force. This buoyant current would separate from the shore when it passed Cape St. James to form an eddy as seen in the laboratory studies of Cenedese and Whitehead (2000). This idea was refined by Di Lorenzo et al. (2005) who reproduced Haida eddies in a ROMS model but, rather than a single separation from the cape producing a Haida eddy, it was found that a succession of smaller $(\approx 80 \mathrm{~km}$ diameter $)$ eddies generated at the cape would merge together to form a large ( $\approx 200 \mathrm{~km}$ diameter, extending to $1000 \mathrm{~m}$ depth) negative vorticity eddy. The generation cycle lasted 3-4 months, consistent with observations (Whitney and Robert, 2002).

In our model runs below we find evidence of dipoles of negative and positive PV eddies. Similar features are seen in satellite images from the area (Fig. 1) where 20-km scale eddies are seen near Cape St. James. These dipoles must have a different generation mechanism than buoyant outflows past the cape since that process will not produce the observed positive potential vorticity. Thomson and Wilson (1987) noted a similar feature near the cape in the geostrophic currents from hydrocasts, with a anti-cyclonic eddy directly west of Cape St. James and a weaker cyclonic eddy found south of the cape. Both eddies had radii near $20 \mathrm{~km}$. Model results with an idealized cape and flat bathymetry implicated tidal rectification as the generation mechanism because current variability in the eddies at fortnightly and monthly periods was quite marked.

The features of interest here are dipoles formed at Cape St. James, likely similar to those observed by Thomson and Wilson (1987). We use a numerical model (Sect. 2) of the Cape St. James region that has a mean stratification and is only forced with tides and find a fortnightly generation of large dipoles via the coalescence of small frictionally generated headland eddies (Sect. 3). The character of the small and large eddies are discussed (Sect. 4) and the implications of our findings summarized (Sect. 5).

\section{Numerical model}

The model used was the Regional Ocean Modeling System (ROMS) version 3.0 (Capet et al., 2008; Warner et al., 2004); largely due to a third-order approximation of advection, ROMS has been successfully employed in studies specifically focusing on mesoscale eddy generation (Foreman et al., 2008; Di Lorenzo et al., 2005). The grid domain is shown in (Fig. 2). The axes are rotated by 39 degrees such that the $\mathrm{x}$ - and $\mathrm{y}$-axes run cross-shelf and along-shelf respectively, similar to models for this region used by Cummins and Oey (1997) (hereafter referred to as CO97) and Di Lorenzo et al. (2005) (DFC05). The horizontal resolution varies in the $\mathrm{x}$-direction from $1.25 \mathrm{~km}$ along the southwestern boundary to $750 \mathrm{~m}$ over the shelf break to a uniform $1 \mathrm{~km}$ inside the shelf break. Resolution in the y-direction is a uniform $1 \mathrm{~km}$. The model is hydrostatic. 


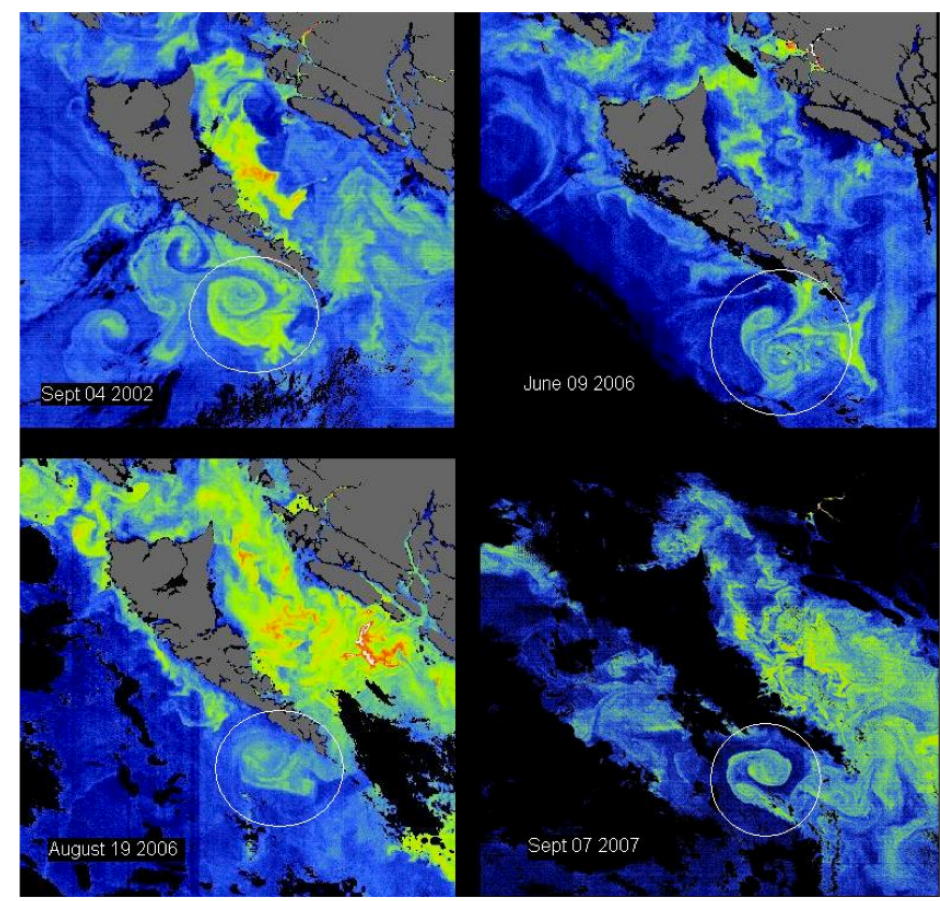

Fig. 1. Representative images from MERIS ocean fluoresence satellite showing eddy dipoles generated near Cape St. James, at the south tip of Haida Gwaii (Queen Charlotte Islands).

In the vertical, we use a sigma co-ordinate system, with 20 levels (similar to CO97 and DFC05). There is increased resolution near the surface to account for the realistic stratification used in the model, defined by the ROMS parameters $\theta_{s}=3$ and $\theta_{b}=0.4$, and using the Song and Haidvogel (1994) stretching function. In $50 \mathrm{~m}$ of water, this yields cells approximately $4 \mathrm{~m}$ near the sea floor, to less than $1 \mathrm{~m}$ near the sea-surface.

The model boundaries were far enough away from the region of interest that baroclinic momentum and tracer boundary conditions clamped to initial conditions were satisfactory; boundary conditions for the barotropic momentum (Flather, 1976) and free-surface (Chapman, 1985) were used. The fidelity of our boundary forcing was not checked but that of the northeast Pacific model from which they were derived was. Table 1 of Foreman et al. (2000) shows that the combined inaccuracy of the M2, S2, K1, and O1 tidal heights with respect to satellite altimeter observations should, on average, be approximately $5 \mathrm{~cm}(<3 \%)$. At Cape St. James, these four constituents account for approximately $70 \%$ of the total tidal range in the diurnal and semi-diurnal frequency bands.

Initial conditions consisted of zero motion and a horizontally uniform stratification representative of the summer stratification for this region (based on the stratification used by CO97); it is defined by linear trends in salinity and temperature near the surface, followed by an exponential drop off at depth (Fig. 2).
Data for tidal forcing at the model boundaries were interpolated from the Foreman et al. (2000) northeast Pacific Ocean model that assimilated tidal harmonics computed from TOPEX/Poseidon altimetry (Cherniawsky et al., 2001). Only the K1, O1, M2, and S2 constituents were used, as in CO97. The barotropic response in CO97 agreed well with the eight constituent models, demonstrating the four constituents unused by $\mathrm{CO} 97$ account for a very small percentage of the total tidal variance in the region. However, this does miss monthly variations due to $\mathrm{N} 2$.

Turbulence closure is achieved via the $k-\epsilon$ closure in the vertical (Warner et al., 2004). In the horizontal, eddy viscosity was a constant $5.0 \mathrm{~m}^{2} \mathrm{~s}^{-1}$ and eddy diffusivity was set to 0 since the tracer advection scheme includes some inherent smoothing.

Bottom stress was calculated as a function of water depth and turbulence length scale at the sea floor from the logarithmic profile suggested by Warner et al. (2004). This requires specification of a bottom roughness, in this case $Z_{\mathrm{ob}}=0.02 \mathrm{~m}$. In $50 \mathrm{~m}$ of water at peak tidal flow, this is roughly equivalent to a quadratic drag coefficient of 0.008 acting on the velocity in the bottom cell. A sensitivity test was run with $Z_{\mathrm{ob}}=0.001 \mathrm{~m}$ (equivalent to a quadratic drag coefficient of 0.003 in $50 \mathrm{~m}$ depth) that produced qualitatively similar results. 

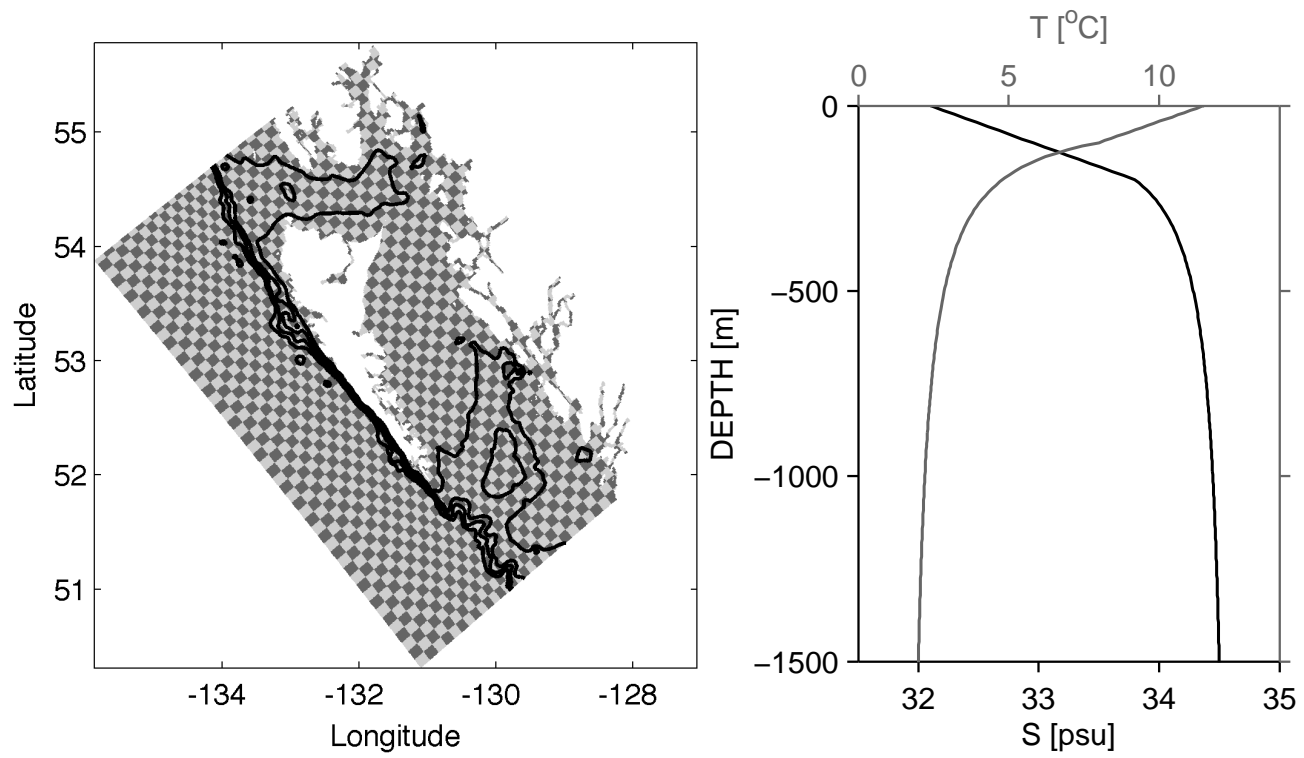

Fig. 2. Alignment of grid over the Queen Charlotte Islands shelf and Sound, every 10th grid point indicated. Stratification is indicated in the right-hand plots.

\section{Potential vorticity balance}

Eddies are diagnosed in the rest of the paper using the full Ertel potential vorticity

$q=(\mathbf{f}+\nabla \times \mathbf{u}) \cdot \nabla b$

where $\mathbf{f}=f \mathbf{k}$ is the Coriolis parameter, $\mathbf{u}$ the velocity, and $b=-g \rho / \rho_{o}$ the buoyancy. Lagrangian changes in $q$ can only be caused by spatially inhomogenous mixing (or thermal forcing) and friction (Marshall and Nurser, 1992):

$\frac{\partial q}{\partial t}=\overbrace{-\mathbf{u} \cdot \nabla q}^{\text {advection }}+\overbrace{(\nabla \times \mathbf{F}) \cdot \nabla b}^{\text {torque }}+\overbrace{(\mathbf{f}+\nabla \times \mathbf{u}) \cdot \nabla \mathcal{D}}^{\text {buoyancy flux }}$.

These terms require considerable care to evaluate in a model like ROMS as discussed in the Appendix.

For the budgets in this presentation, PV is integrated from the depth $z_{24}$ (where $\sigma_{\theta}=24 \mathrm{~kg} \mathrm{~m}^{-3}$ ) to the surface to arrive at a vertically integrated PV.

$\mathcal{Q}=\int_{z_{24}}^{0} q \mathrm{~d} z$

Each location in the model domain is assigned a vertically integrated rest-state PV

$\mathcal{Q}_{o}=\int_{z_{24}}^{0} \mathbf{f} \cdot \nabla b_{o} \mathrm{~d} z$

and we often present the anomaly $\Delta \mathcal{Q}=\mathcal{Q}-\mathcal{Q}_{o}$. Barring changes in $b$ with time, we can integrate to see that

$\Delta Q \approx \Delta b\left\langle\nabla_{H} \times \mathbf{u}\right\rangle_{0}^{\sigma_{\theta}}$ where $\Delta b$ is the background buoyancy difference from the surface to $z_{24}$. Therefore the anomaly, $\Delta Q$, is just the average vertical component of the relative vorticity from the sea surface to the rest depth of $\sigma_{\theta}=24 \mathrm{~kg} \mathrm{~m}^{-3}$, which is about $100 \mathrm{~m}$.

\section{Results}

\subsection{Overview}

The most striking feature when running a tide-only simulation is the formation of self-propagating mesoscale eddy dipoles at Cape St. James (Fig. 3; there are also two Supplement movies in mpeg-4 format). These eddies are approximately $20 \mathrm{~km}$ in diameter and counter rotating (Fig. 4) with velocities in excess of $0.25 \mathrm{~m} \mathrm{~s}^{-1}$. Tracking the eddies, we see that they move towards the south with a speed of approximately $6 \mathrm{~km} \mathrm{~d}^{-1}$. A new eddy dipole can be identified every 14 days, forming at the end of spring tides and propagating offshore with neap tides.

Significant vorticity anomalies are also advected northwards along the west shore of Haida Gwaii (Fig. 3). A semipermanent dipole can be seen at approximately $y=200 \mathrm{~km}$. This feature does not appear to separate from the island and migrate into the interior, and we do not pursue it further here.

The source of the vorticity in the large eddies is the strong tidal flows near the cape (Fig. 5). Small ( $\sim 3-\mathrm{km}$ radius) dipoles are generated each tide, some of which migrate into a "coalescence zone" where they merge with previously generated eddies to form the mesoscale eddies. 

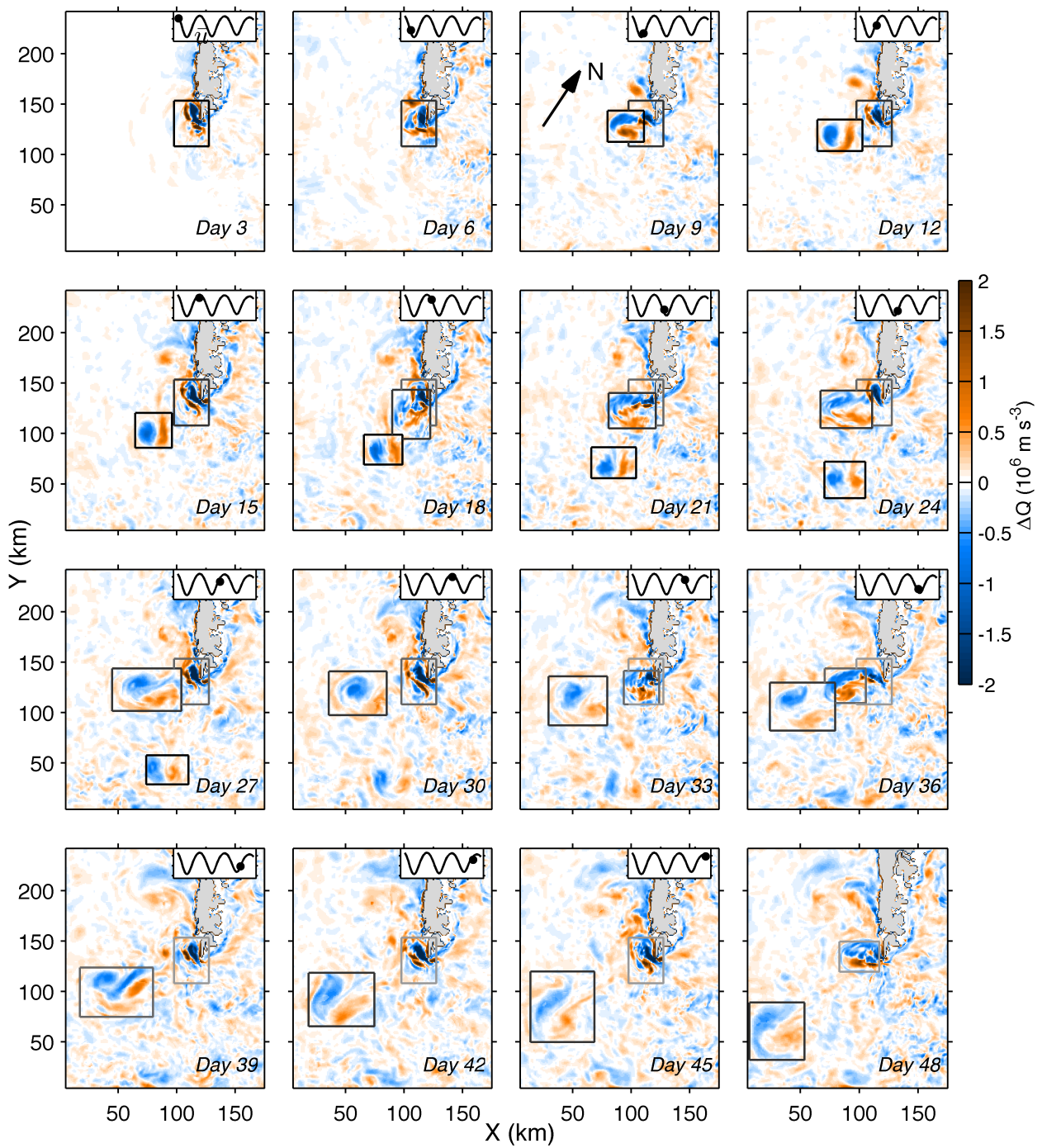

Fig. 3. Integrated PV in coalescing eddies over the whole model run showing the propagation of dipoles offshore. PV has been integrated from $\sigma_{\theta}=26 \mathrm{~kg} \mathrm{~m}^{-3}$, or approximately $100-\mathrm{m}$ depth, to the surface. Gray boxes indicate eddy dipoles tracked below. Note the change in the color limits compared to Fig. 5. The inset box in each panel is the envelope of mean cross-shelf tidal velocity in a 5-km box near the cape, with a dot representing the tidal velocity for the panel pictured. Highs denote spring tides, lows are neap tides.

Negative potential vorticity (PV) generation at Cape St. James occurs on the ebb tide, and positive PV generation on the flood (Fig. 5). The generation and subsequent coalescence of large-scale eddies follows a repeatable pattern. Early in flood tide, a small patch of positive PV (red, radius of $\sim 3 \mathrm{~km}$ ) forms on the east side of the cape (Fig. 5, hour 6.5 ; note that there are two other patches of positive PV identified from previous tides). When the tide ebbs (hour 12.516.5), this patch is advected westward and negative PV (blue) is generated on the west side of the cape, although this generation is not nearly as clear as the positive PV generation due to the lingering presence of negative $\mathrm{PV}$ in the region from previous ebbs. During the following flood (hours 18.5, 20.5), the original eddy is advected back eastward and a new posi- tive eddy is formed to the east of the cape (noted with a gray box). During the strong ebb that follows, the original eddy is pushed further offshore and to the south where it merges with a more diffuse larger eddy. The new eddy (gray box) is pushed to the north with tidal flow that rounds the cape.

\subsection{Tidal phase and coalescence}

The tidal inequality leads to the coalescence. In the example above, the positive eddy advected west by a weak ebb tide coalesced into the positive half of the dipole, while the eddy advected by a strong ebb was swept away from the cape and to the north. Here we track eddies over a number of tidal cycles and see that pattern repeated in the 48 days of simulation (Fig. 6), with coalescing positive PV anomalies formed 


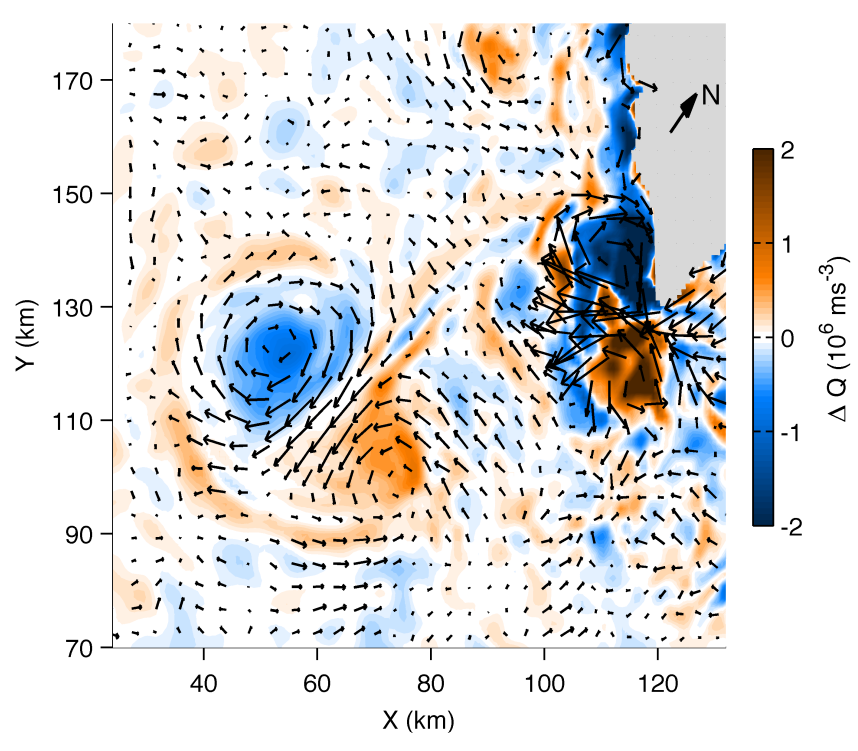

Fig. 4. Vertically integrated potential vorticity for day 31 of a tidal model run. Vorticity anomalies are concentrated at the cape, but a mesoscale vortex dipole has organized and is propagating south west.

on strong floods followed by weak ebbs. Tracking the eddies in detail, we see that those that coalesce follow a path very similar to the example above, with the eddies being pushed further to the Southeast during the flood tide, and then further to the south during the weak ebb tide (Fig. 7b). Positive eddies that went north were pushed further off the cape by the strong ebb tides.

In each spring-neap cycle there are 5-7 positive PV eddies which coalesce (Fig. 7b). There are usually 1-2 more which enter the coalescence zone before the others, but these quickly mix with the negative $\mathrm{PV}$ in the region and so do not contribute towards forming the final large eddy. The first eddy marked as a coalescing eddy mixes slightly, but stays intact for the most part. Each subsequent eddy which enters the coalescence region interacts with the eddies already present, deforming and wrapping around each other until a single, larger $(\approx 12 \mathrm{~km}$ radius), eddy is formed.

The above tracking was for positive PV. We do not track specific patches of negative PV from the cape to the coalescence zone because isolating negative PV is complicated by significant negative PV that remains attached to the cape. However, qualitatively a large negative PV feature emerges in this region next to the positive PV feature, growing at a similar rate. Thus, a large dipole is produced to the west of the cape due to coalescence of small eddies generated at the cape. There were a number of eddies during neap tides that were less easy to classify, so we call them "Mixed" and "Early coalescing". The "mixed" eddies tend to not be advected very far to the west and lose their identity to mixing with negative PV near the cape. The "early" eddies occur during weak tidal flows and tend to merge with whatever eddy forms on the next tidal cycle.

The strong-flood/weak-ebb tidal inequality arises during the second half of the spring-neap cycle (Figs. 6, 7a); during the first half, the flow almost does not ebb at all and the eddies merge with the next tide ("Early"). A model run with just a semi-diurnal $M_{2}$ (Fig. 8) has vorticity generated at the cape, but no eddy dipoles form south of the cape. The quasisteady feature on the west side of the island is still present $(y \approx 170 \mathrm{~km})$

\subsection{Character of the large dipoles}

The small eddies coalesce into large dipoles south of the cape. In an example dipole (Fig. 9) the clockwise (counter clockwise) eddy has a diameter of approximately $30 \mathrm{~km}$ $(25 \mathrm{~km})$ and extends to $100 \mathrm{~m}(150 \mathrm{~m})$ depth; with these dimensions, the total volume of each eddy is close to $7 \times$ $10^{10} \mathrm{~m}^{3}$. Velocities reach up to $20 \mathrm{~cm} \mathrm{~s}^{-1}$ in each eddy. The dipole travels southwestward at a rate of $6 \mathrm{~km} \mathrm{~d}^{-1}$ (calculated from the motion of the dipole in the first cycle as it is the only one to move a significant distance in the length of the model run). While the density within the negative eddy is approximately constant at this depth (Fig. 9c), there is upwelling of isopycnals within the positive eddy (Fig. 9d). This dipole is representative of the others we simulated, though each has slightly varying sizes and strengths (Fig. 3).

\subsection{Frictional generation of positive PV}

The PV anomalies in the headland eddies are generated by friction at Cape St. James (Fig. 10). As the tide ebbs (floods) at the cape, negative (positive) PV is generated where the amount of PV generated varies with the strength of the tide. The role of diapycnal mixing in generating the eddies is insignificant (Fig. 10, gray line), so the dominant source of vorticity is frictional torque (thin black line) which balances the rate of change in the volume except for a relatively small net advection. The advection is most notable during strong ebbs where PV is being advected west of the cape.

The source of the torque is bottom friction induced by the shallow water and faster flows around the cape (Fig. 11). Positive PV is generated during flood tides and negative during ebb almost everywhere around the cape but particularly concentrated near the cape tip.

\subsection{Efficiency of PV generation}

The largest component of vorticity production near the cape is friction. Here we note that this friction is more than adequate to generate the observed vorticity in the tidal eddies, and that these small eddies have more than enough vorticity to produce the mesoscale dipoles.

Approximately $450 \mathrm{~m}^{3} \mathrm{~s}^{-3}$ of positive $\mathrm{PV}$ is generated if we integrate over a flood tide (Fig. 12). If we compare this to the vorticity in the qualitatively tracked $6-\mathrm{km}-\mathrm{by}-6-\mathrm{km}$ tidal 

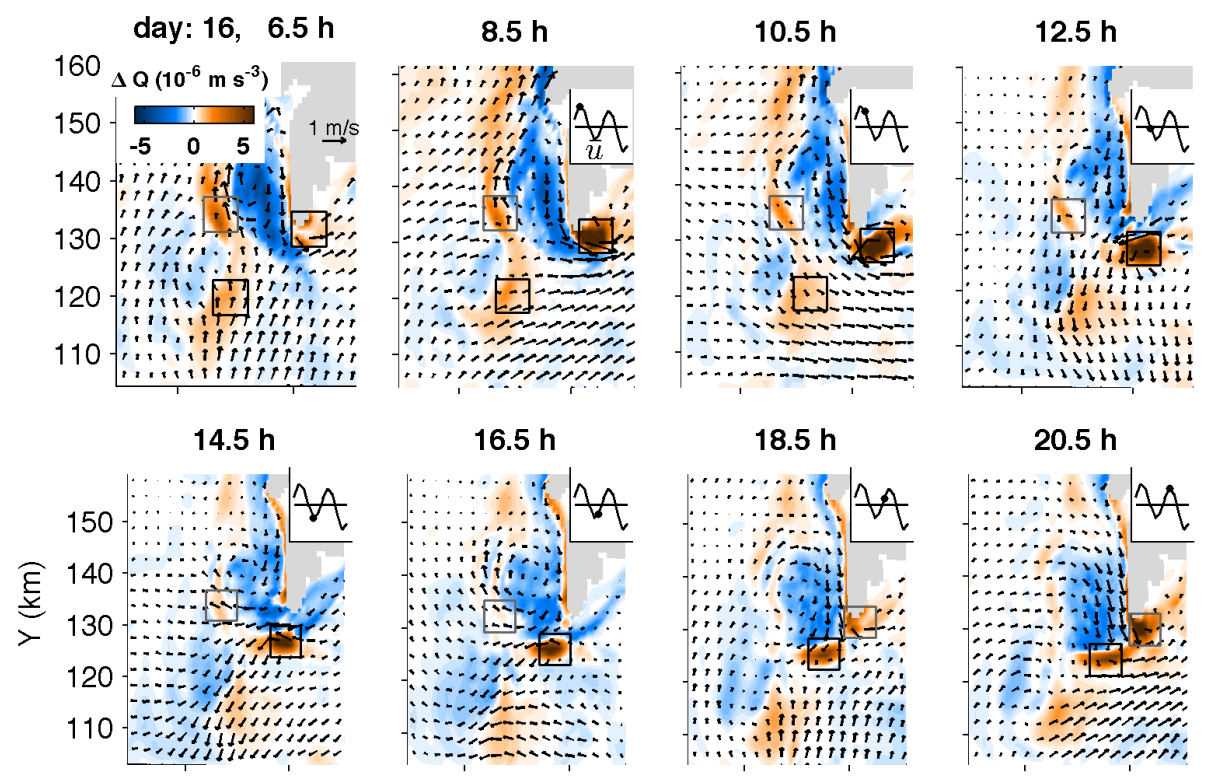

$22.5 \mathrm{~h}$

$0.5 \mathrm{~h}$
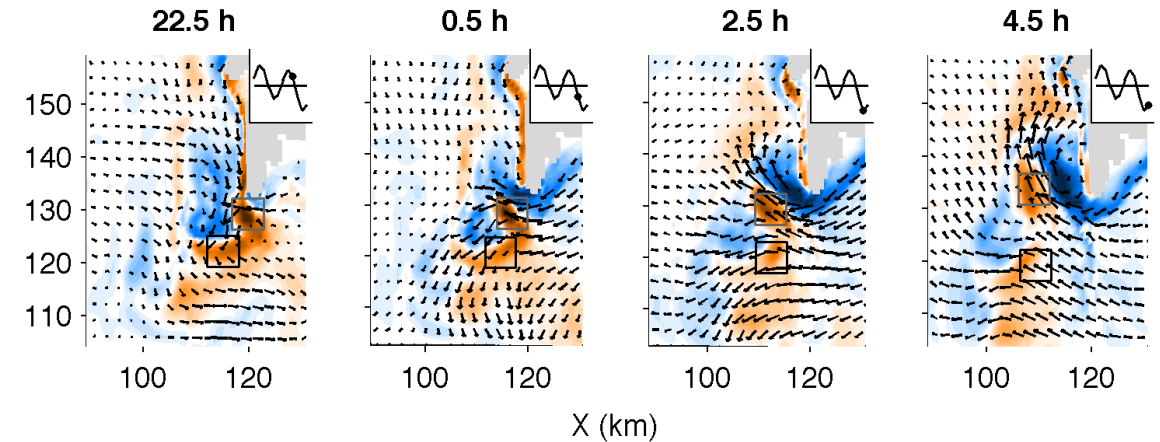

Fig. 5. Tidal evolution of vertically integrated potential vorticity anomaly for $24 \mathrm{~h}$ of the model run. PV has been integrated as in Fig. 3 . Arrows are velocities at 50-m depth; mean tidal flow with the inset panel. Positive vorticity anomalies are identified and tracked with boxes - black boxes coalesce into the mesoscale features south of the cape, gray boxes advect northwards.

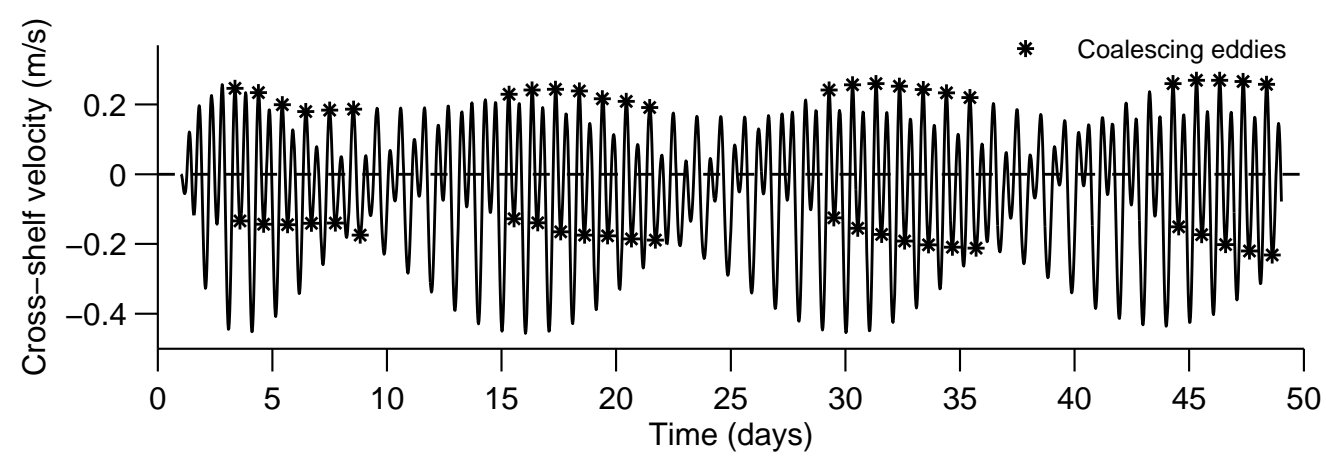

Fig. 6. Timing of coalescing eddy generation for whole model run. Eddies are advected into the coalescing zone during strong floods followed by weak ebbs.

eddies (Fig. 5) we see that the eddies initially gain something like half this integrated positive PV. This vorticity rapidly drops, however, to a value less than $50 \mathrm{~m}^{3} \mathrm{~s}^{-3}$, or $10 \%$ of the total generated that tidal cycle. The remainder of the pos- itive PV leaks out of the identified eddy cores, or mixes with the surrounding negative PV diluting its strength, therefore we put initial generation of tidal headland eddies at $10 \%$ of the available positive PV. 

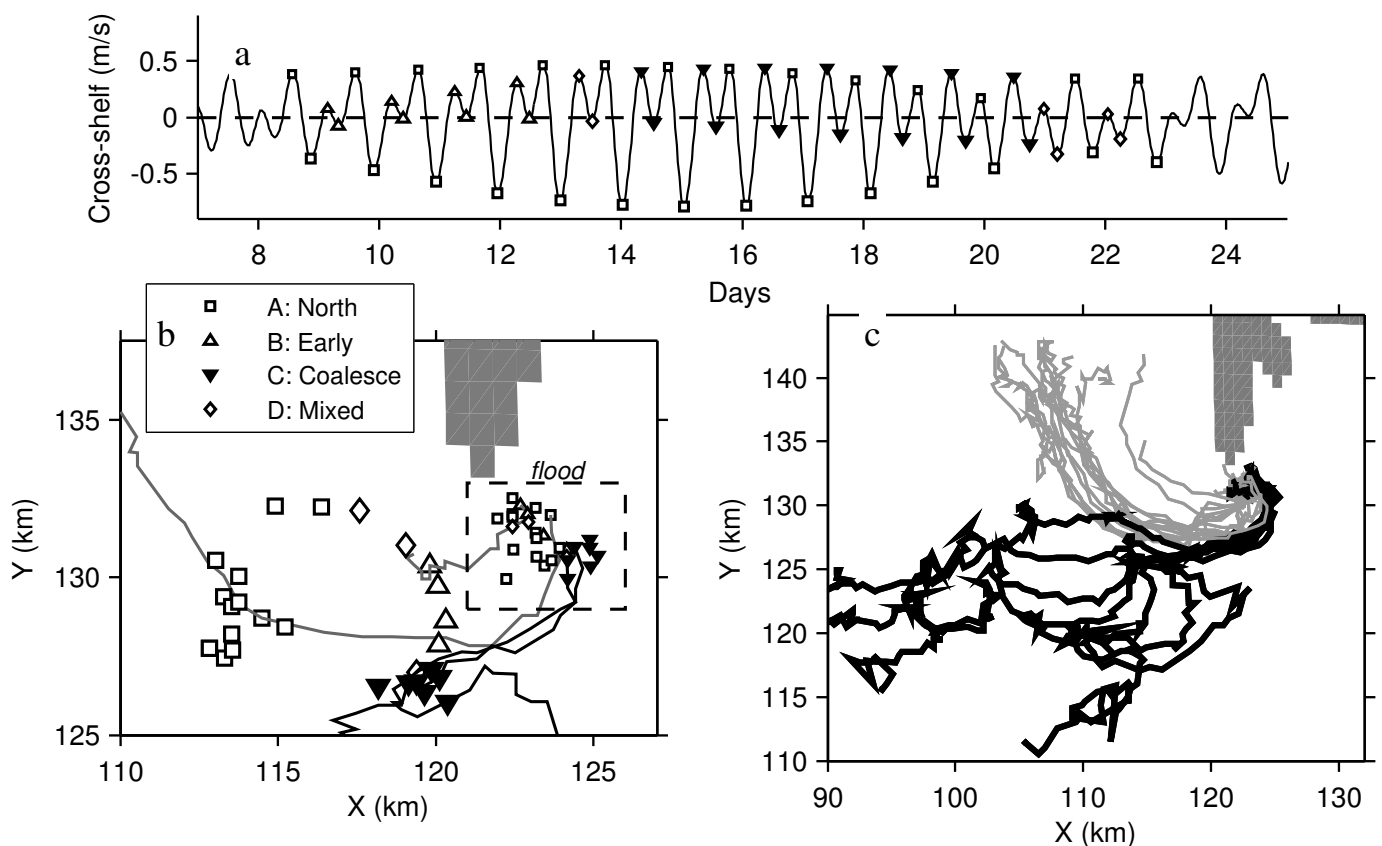

Fig. 7. Effect of advection on the fate of cape-generated vorticity. (a) The cross-shelf barotropic velocity in the vicinity of the cape. Symbols mark the times plotted in (b). (b) Fate after half a tidal cycle of positive PV eddies generated for each flood over a spring-neap cycle. Symbols represent whether the eddies coalesced or not, with four subjective divisions indicated. Smaller symbols are the center of the eddies at the peak flood tide they are generated on; larger symbols are where they are at peak ebb half a tidal cycle later. "Coalescing" eddies tend to be formed SE of other eddies and are advected to the SW by a weak following tide. Two sample "coalescing" (black) and two "non-coalescing" tracks (grey) are also shown. (c) The tracks of all the eddies indicated in (a) and (b): grey tracks do not coalesce, corresponding to open symbols; black tracks do coalesce and correspond to the black triangles in (a) and (b).

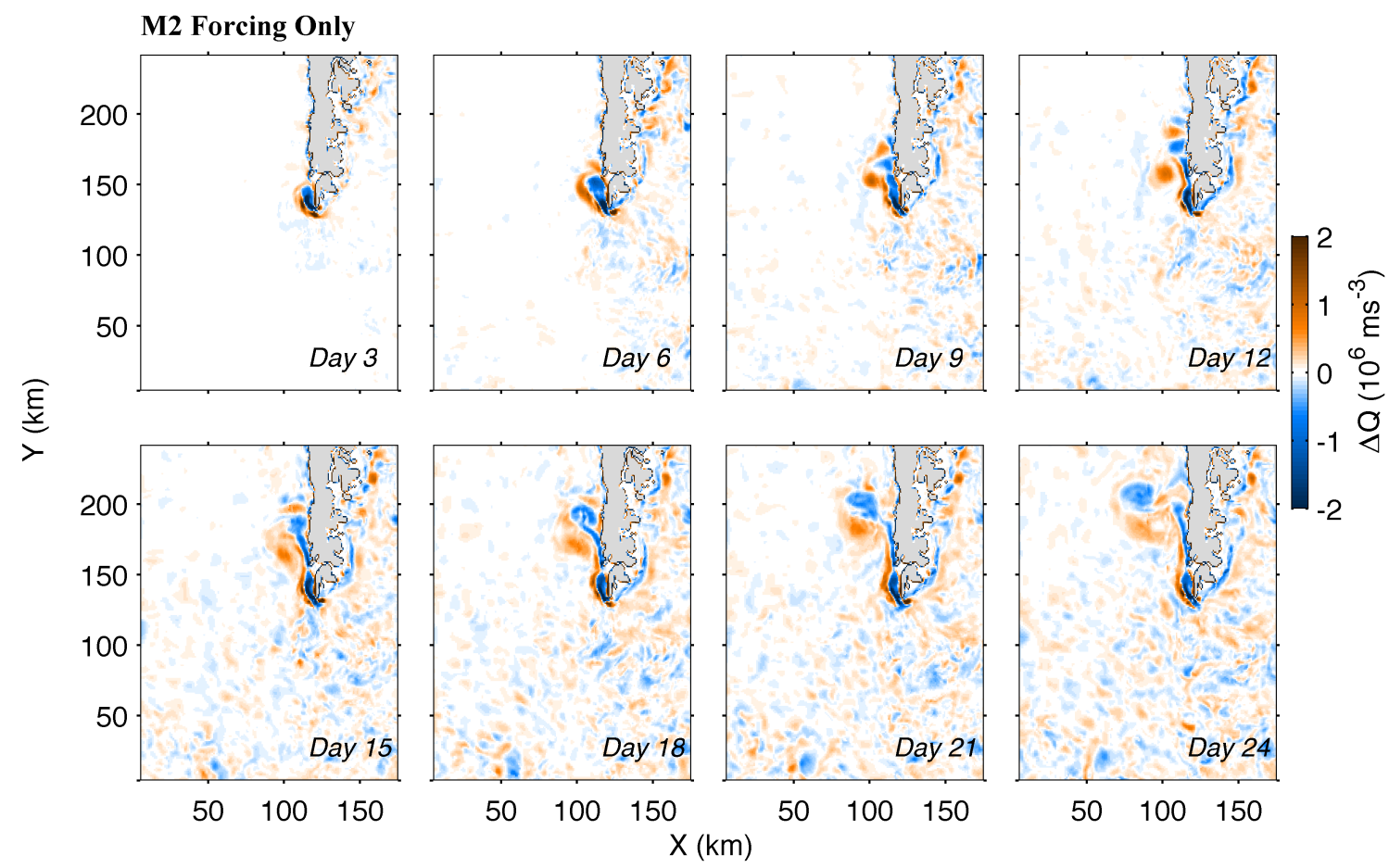

Fig. 8. Results of a model run the same as the base run, but with just $M_{2}$ tidal forcing. 

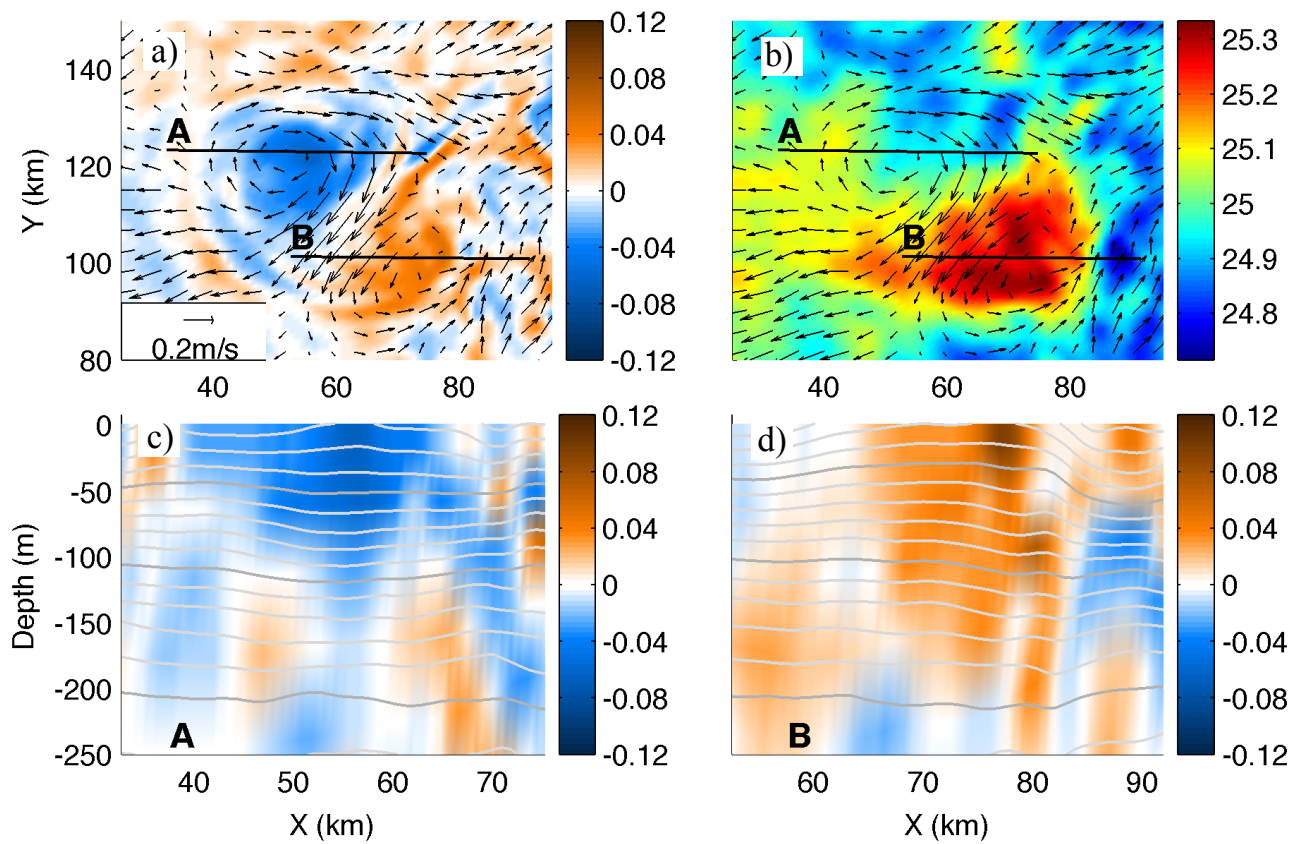

Fig. 9. Final eddy pair observed southwest of the cape from day 31 (Fig. 4). (a) PV and velocity vectors at the surface. (b) Potential density at the surface (c) velocity and isopycnals along transect $\mathrm{A}$, the negative side of the dipole and (d) along transect $\mathrm{B}$, the positive side.
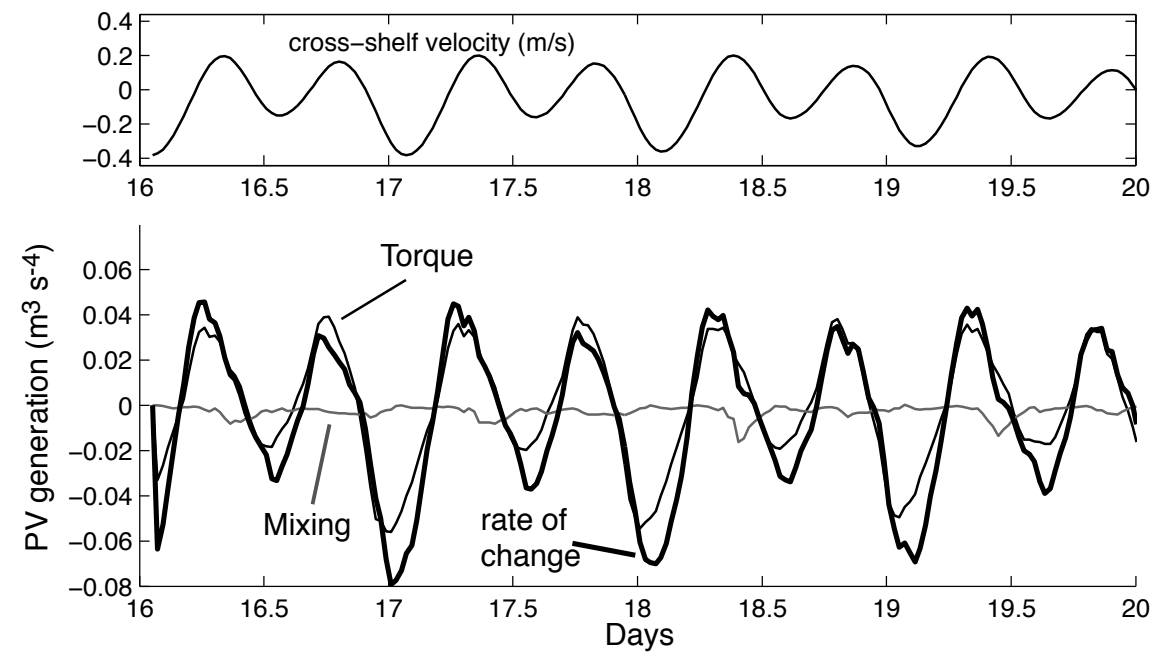

Fig. 10. PV budget over a $20 \times 20 \mathrm{~km}$ box over the cape. The term due to mixing inhomogeneity is very small. The difference between the torque generation and the rate of change of $\mathrm{PV}$ in the region is due to advection.

The coalescence of the small eddies into large dipoles is more efficient. Tracking the big eddies (boxes, Fig. 3) shows that they have an initial growth phase as tidal eddies coalesce before the eddy moves offshore (Fig. 13). This is followed by a large drop in integrated PV as the final organized form of the dipole emerges. The total PV in the first eddy is less than the subsequent eddies, and tracking the PV becomes complicated as the second and third eddies merge.

Looking more closely at the second mesoscale dipole formed in the model run, seven small eddies have coalesced to form the larger eddy (Fig. 13), containing a positive PV anomaly of approximately $490 \mathrm{~m}^{3} \mathrm{~s}^{-3}$. This anomaly is actually larger than the amount we would assess by simply summing the PV from the eddies as accounted for in Fig. 12, indicating that our accounting has allowed some of the PV to leak out of the $6 \times 6 \mathrm{~km}$ boxes we used to track the tidal eddies. Rather than attempt a more convoluted accounting, however, we simply point out that the growth of the mesoscale eddies is consistent with the amount of PV in the headland eddies that feed them. 

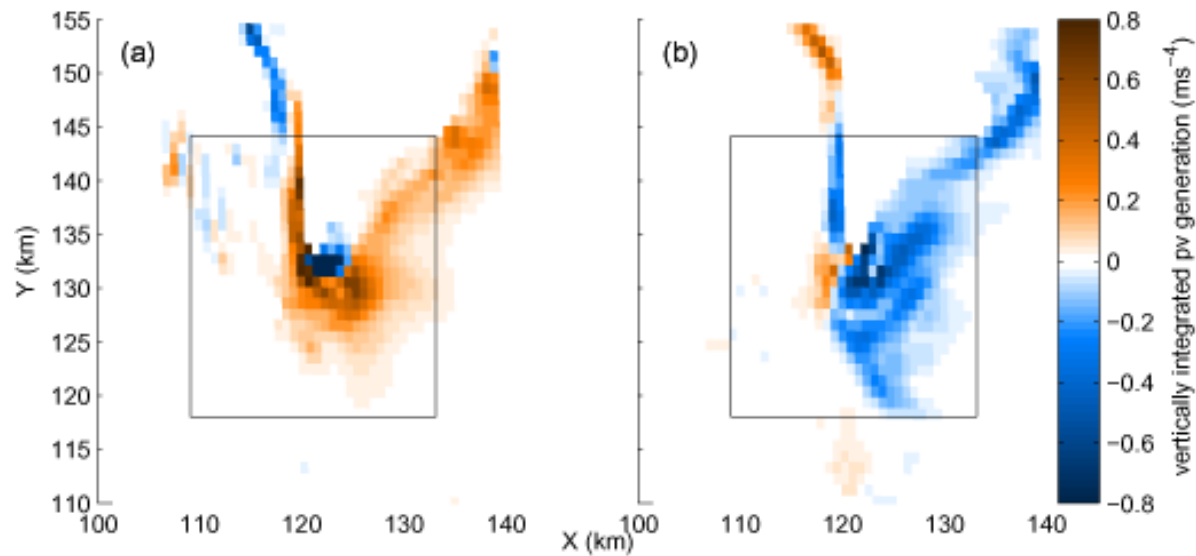

Fig. 11. Vertically integrated PV generation near the cape during (a) peak flood and (b) peak ebb tides.
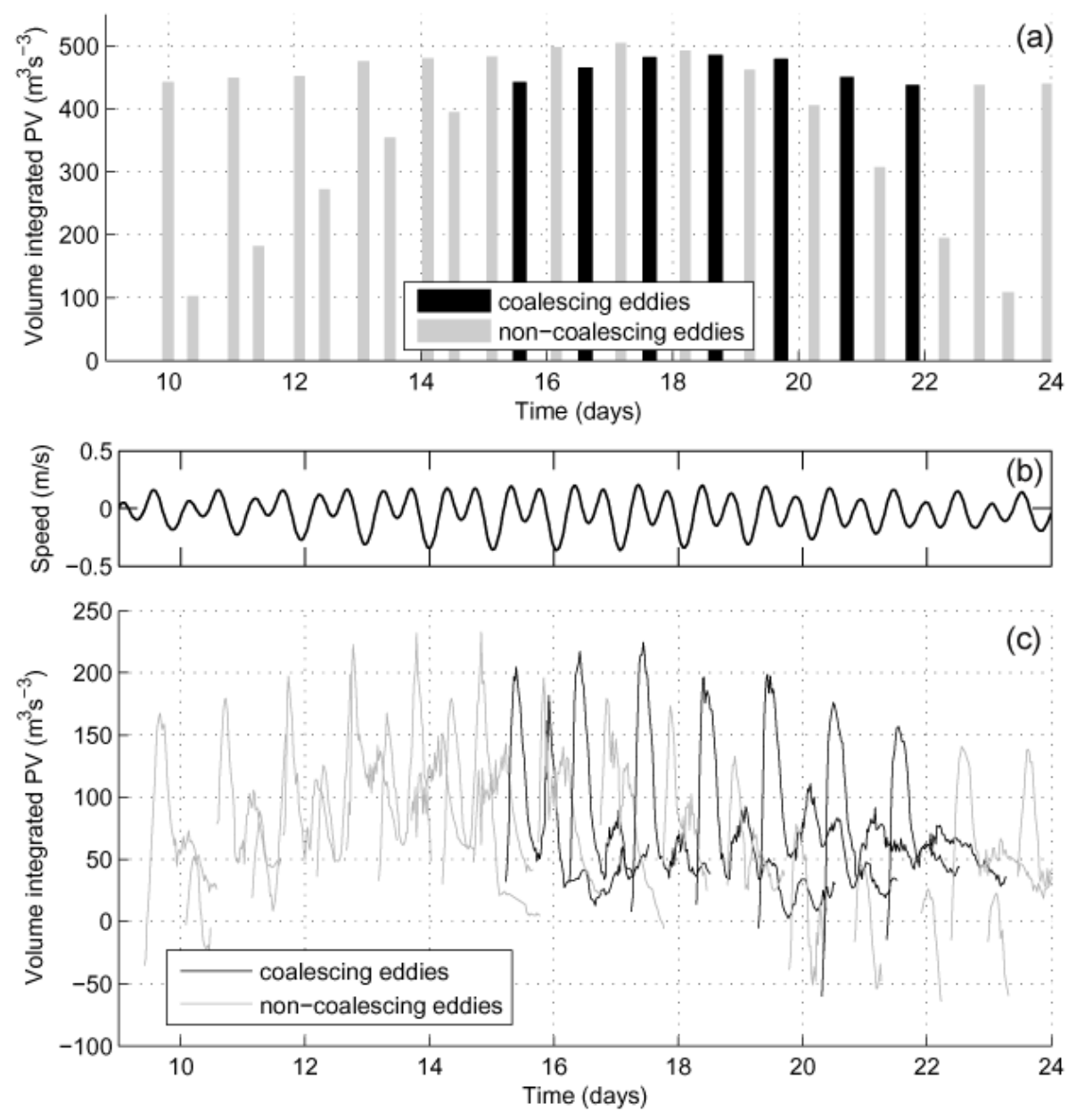

Fig. 12. (a) Positive PV generated by friction on each flood tide between the first and second neap tides in the generational region shown in Fig. 11. Bars shown in black indicate eddies which coalesce. (b) Tidal speed near the cape. (c) Volume-integrated potential vorticity contained in each positive-PV eddy generated between the first and second neap tides. Each eddy was tracked until it became obvious which direction it was heading, so some eddies are tracked longer than others. The eddies which eventually coalesce to form the feature of interest are shown in black, all other eddies are shown in grey. The cross-shelf tidal velocity is shown in the upper panel; we can see here that the eddies which coalesce are generated on a strong flood tide which is followed by a weak ebb. 


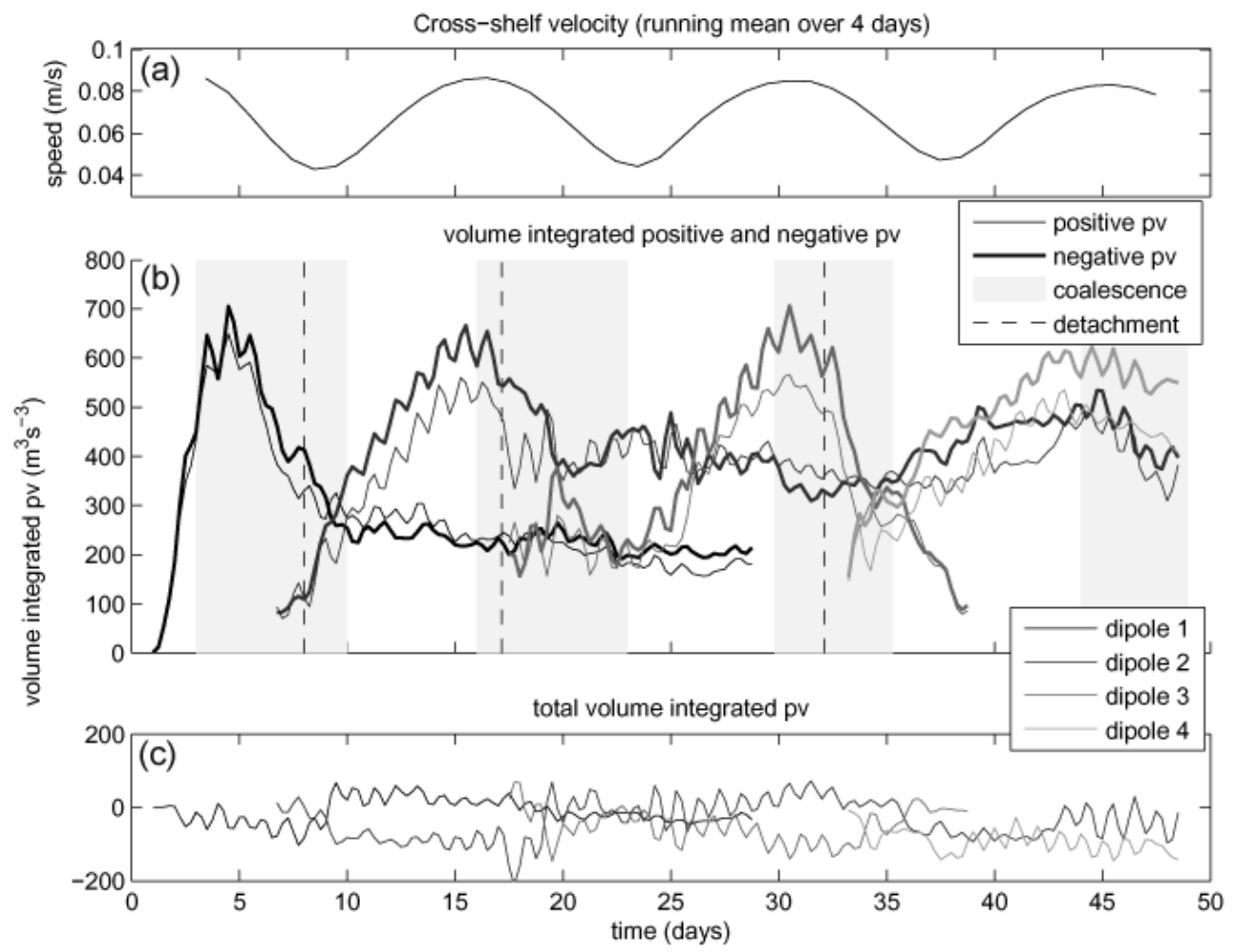

Fig. 13. (a) Spring-neap envelope of the cross-shelf tidal velocity near the cape. (b) Volume-integrated PV for each of the positive and negative PV eddies in the large dipoles. The horizontal volumes over which this integration is accomplished are shown in Fig. 3; the integration is performed vertically between the surface and $\rho=26 \mathrm{~kg} \mathrm{~m}^{-3}$. Both the middle and lower panels show that the amount of PV contained in each eddy of the dipole is approximately equal. The dashed line indicates when the dipole has detached from the cape; this measure is highly imprecise, having simply been obtained by eye; errors on order of one day are likely. (c) Sum of positive and negative vorticity in the dipole pairs.

After initially forming, the second mesoscale eddy stabilizes to approximately $400 \mathrm{~m}^{3} \mathrm{~s}^{-3} \mathrm{PV}$ (Fig. 13). Again, this is an approximate value due to variability in both the amount of PV seen in the small eddies prior to coalescence and the length of time it takes small eddies to coalesce; the eddies that coalesce first do so relatively quickly, within $18 \mathrm{~h}$ of being generated; the last few eddies may take more than $36 \mathrm{~h}$ to coalesce. This difference is due to the large dipole beginning to move away from the cape.

\subsection{Asymmetry of eddy-shedding}

The asymmetry of dipoles shedding to the west of the cape and never to the east is due to a tidally-rectified mean current which travels southwest across the cape tip (Fig. 14). Crawford et al. (1995) noted a consistent $20 \mathrm{~cm} \mathrm{~s}^{-1}$ flow near the tip of the cape and concluded it was due to tidal rectification. The negative PV eddy is seen in this figure in the velocity signal to the west of the cape. A northward current is also seen running along the shelf break $(X \approx 110 \mathrm{~km})$, as seen in other tidally-driven models for this region (Cummins and Oey, 1997).

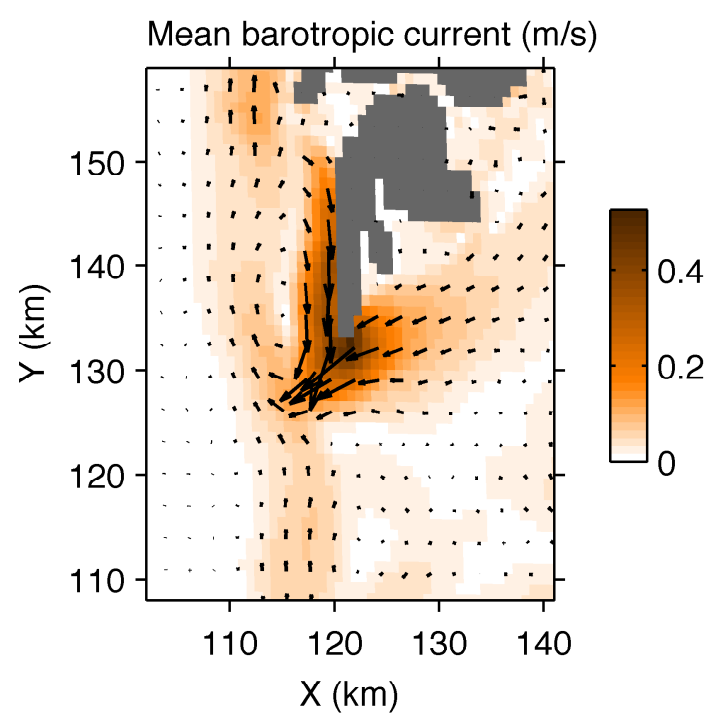

Fig. 14. Mean barotropic current near the cape. 


\section{Eddy characteristics}

\subsection{Eddy size}

With radii of approximately $10-15 \mathrm{~km}$, the lateral size of the eddies in the final dipole is smaller than the first baroclinic Rossby radius, $\approx 20 \mathrm{~km}$ in the deep ocean at this latitude (Chelton et al., 1998). The tidal eddy size can very roughly be estimated by noting that the region of high torque near the cape is approximately $9 \mathrm{~km}$ wide with flows averaging $0.25 \mathrm{~m} \mathrm{~s}^{-1}$ for a total area corresponding to an eddy with a radius of $4 \mathrm{~km}$, similar to the $3-\mathrm{km}$ tidal eddies observed.

\subsection{Shedding frequency}

The situation at the cape tip is analogous to flow separation around a blunt object, with a localized torque exerted by a boundary layer resulting in separation. Separation bubbles behind blunt obstacles sometimes shed into the interior. For a buoyant outflow with strong rotation this occurs when the eddy reaches the size of a Rossby radius (Cenedese and Whitehead, 2000). When rotation is not important then the shedding frequency is

$n=0.2 \frac{U}{d}$

where 0.2 is the Strouhal number, $U=0.2 \mathrm{~m} \mathrm{~s}^{-1}$ the mean flow, and $d \approx 4 \mathrm{~km}$ the scale of the cape (Kundu, 1990). This implies less than one cycle a day, so we would not expect more than one eddy to be shed per tidal cycle.

\subsection{Eddy-pairing}

We noted above that the diurnal inequality in the tides was necessary for some of the tidal eddies to coalesce into the dipole. Following (Signell and Geyer, 1991), this can also be approached by comparing the timescale of eddy advection to the tidal period, or the Keulegan-Carpenter number $K_{c}=$ $T U_{o} / a$, where $T$ is the tidal period, $U_{o}$ is the tidal velocity, and $a$ the along-flow width of the cape $a \approx 2 \mathrm{~km}$. For the weak ebbs where the eddies coalesce, $U_{o}<0.2 \mathrm{~m} \mathrm{~s}^{-1}$ and $K_{c}<4.5$ (Fig. 7a); for the strong ebbs $U_{o}>0.5 \mathrm{~m} \mathrm{~s}^{-1}$ and $K_{c}>12$. Signell and Geyer (1991) found that low- $K_{c}$ flows tend to have interacting eddies as seen during our weak ebb tides, whereas high- $K_{c}$ flows tend to sweep the eddy out of reach of interacting with the headland. The phenomenology in our case is a little richer, as we have a tidal inequality that can create a larger negative eddy than positive, leading to more complex interactions, but our results are in rough agreement with Signell and Geyer (1991).

For shallow water, the spin-down time of the eddies is also important, represented by a frictional Reynolds' number $R e_{\mathrm{f}}=H / C_{\mathrm{d}} a$, where $H$ is the water depth and $C_{\mathrm{d}} \approx 0.008$ is the seafloor drag co-efficient. For $H \approx 100 \mathrm{~m} R e_{\mathrm{f}} \approx 6$, which means that the influence of the seafloor is not very large, but may account for some of the initial loss of vorticity in the tidal eddies after their formation.

\subsection{Advection of eddy dipole}

The large dipole propagates towards the south at approximately $6 \mathrm{~km} \mathrm{~d}^{-1}$, which is somewhat surprising given the tendency of mesoscale monopoles to propagate to the westward due to the planetary beta effect (Cushman-Roisin et al., 1990), or northward along the continental slope due to the topographic beta effect. Under the beta effect an eddy would also be expected to propagate considerably slower, at approximately $1 \mathrm{~km} \mathrm{~d}^{-1}$ for the stratification and latitude here (Cushman-Roisin et al., 1990), a speed shared with the openwater Haida eddies (Gower and Tabata, 1993; Crawford, 2002). Therefore the dynamics here are not likely to be the usual self-induced beta-effect drift.

A better analogy for the fast propagation speed may be self-advecting dipoles. For a vortex pair in a non-rotating barotropic flow: $c=\Gamma / 4 \pi d$, where $\Gamma$ is the circulation in each eddy and $2 d$ the distance between the centers of the eddies. Evaluating this for the eddies observed here we arrive at $10 \mathrm{~km} \mathrm{~d}^{-1}$ which is faster than the observed translation speed, but much faster than the beta-drift model.

A possible explanation for the slower self-advection is that the dipole starts in shallow water and then moves out into the deep water. The vorticity is largely confined to the surface waters (Fig. 9) but likely has a form drag exerted on it by the water below that slows the propagation speed down. Eddies in a stratified environment can radiate "lee waves" (Afanasyev, 2003) that require energy from the mean flow. However we do not know of a good theory for determining how much this effect would slow down the self advection of the dipole, and leave it as a subject for future study.

The dipoles generated are of practical interest only if they last long enough to transport whatever nutrients or other tracers they may contain over long distances. We can estimate the decay rate of the first dipole as being about $10 \%$ between days 10 and 20 (Fig. 13). Assuming an exponential decay, this means the PV in the dipole will decay to $10 \%$ of its original value in 219 days. At $\sim 6 \mathrm{~km} \mathrm{~d}^{-1}$, the dipole will have traveled $1314 \mathrm{~km}$, a significant distance into the Gulf of Alaska. It should be cautioned that the advection of these eddies is in the absence of local winds or basin-scale flows, and that they would be expected to refract in the real ocean.

\section{Summary and discussion}

Here we have demonstrated a unique mechanism for the creation of mesoscale potential vorticity anomalies, and in particular of cyclonic PV anomalies. Anti-cyclonic PV anomalies are very prevalent because they are the natural result of gravitational collapse of mixing regions, whereas eddies of both signs are understood to be produced by separation of 


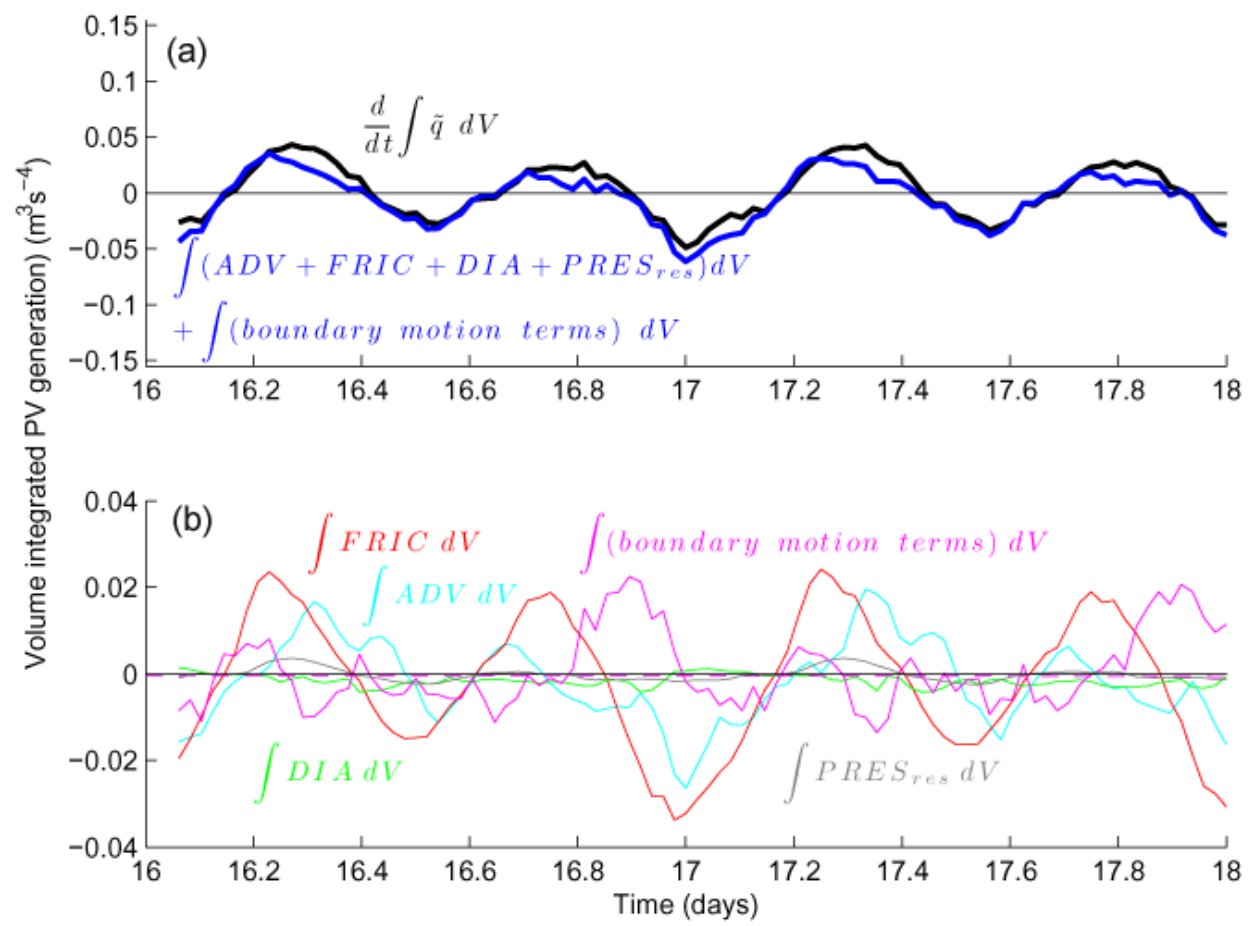

Fig. 15. PV budget over box near Cape St. James, between the surface and $\sigma_{\theta}=26 \mathrm{~kg} \mathrm{~m}^{-3}$ : (a) rate of change compared to source terms; (b) source terms.

buoyant or wind driven mean flows. Here, however, the alternating tidal flows past a cape were observed to coalesce into a dipole of PV anomalies that then propagated away from the boundary.

Of course there is nothing new about the formation of tidal headland eddies. They are common in coastal environments (i.e. Geyer and Signell, 1990; Klymak and Gregg, 2001; Edwards et al., 2003). The potential of Cape St. James to generate tidal vorticity has also been previously recognized by (Thomson and Wilson, 1987) who found observational and numerical modeling evidence of positive vorticity on the east side of the cape, and negative on the west. What is unique here is the coalescence of this vorticity into a large-scale dipole that propagates offshore faster than implied by the beta drift.

The dipoles that form are distinguished from the larger Haida Eddies that occasionally form at Cape St. James (Crawford et al., 2002). The Haida Eddies are all anticyclonic (negative PV), significantly larger, with radii greater than $40 \mathrm{~km}$, and move much slower (about $1 \mathrm{~km} \mathrm{~d}^{-1}$ ). Their formation is consistent with the mechanism proposed by D'Asaro (1988) for a mean flow separating from a sharp headland (Di Lorenzo et al., 2005), where the mean flow at Cape St. James is believed to come from the spring runoff changing the buoyancy in Queen Charlotte Sound, or from wind forcing. Haida eddies may be the dominant local vorticity signal, but their mechanism cannot produce the positive vorticity observed in some of the satellite images (Fig. 1).
That said, we do not want to overstate the case that the eddies observed in this model are important or cause the positive vorticity features seen in the satellite pictures (Fig. 1). It is conceivable that the satellite observations could be explained by a sudden relaxation of a south wind that releases buoyant water from Queen Charlotte Sound, accelerates around the Cape and induces positive vorticity as it laterally shears with the ambient water. Certainly the satellite images are reminiscent of this process from laboratory studies. However, whether such a flow could create shears strong enough to induce such a strong potential vorticity signal is not clear. We consider the tidal mechanism demonstrated here to be intriguing as it is a steady source of vorticity that may act year round and in many different locales. The particular implication for Cape St. James is that the transmission of high nutrient, coastal water into the Northeast Pacific is not restricted to the winter when Haida Eddies are primarily generated.

\section{Appendix A}

\section{Potential Vorticity budget}

We are interested in understanding the formation of eddies in the model. Eddies are characterized by anomalous PV, so we diagnose the change of $\mathrm{PV}$ in regions of the model. The chosen control volume is bounded in the horizontal by 
along-shore and across-shore transects and in the vertical by two isopycnals. A logical choice for this analysis is a PV budget (Thomas et al., 2008, T08). T08 wrote a PV budget for use with a ROMS model to investigate the generation mechanism of intrathermocline eddies at wind-forced fronts. The model this budget was based on had a flat bottom, constant horizontal resolution and a rigid lid, so this budget was adapted for use with the more realistic model used here. This budget was based on the equation for the full Ertel PV (Gill, 1982):

$q=(\mathbf{f}+\nabla \times \mathbf{u}) \cdot \nabla b$

Changes in PV arise from advection, frictional torques, and mixing as shown by each term in the following equation (Marshall and Nurser, 1992):

$\frac{\partial q}{\partial t}=\overbrace{-\mathbf{u} \cdot \nabla q}^{\text {advection }}+\overbrace{(\nabla \times \mathbf{F}) \cdot \nabla b}^{\text {torque }}+\overbrace{(\mathbf{f}+\nabla \times \mathbf{u}) \cdot \nabla \mathcal{D}}^{\text {buoyancy flux }}$.

The friction term introduces PV through torque exerted by body forces acting perpendicular to the density gradient which is primarily vertical in the ocean. To good approximation all friction forces are given by

$\mathbf{F}=\nabla \cdot\left(K_{\mathrm{m}} \frac{\partial \mathbf{u}_{h}}{\partial z} \hat{k}\right)$

where $K_{\mathrm{m}}$ is the vertical diffusion of momentum in the model. The buoyancy flux term is given by $K_{\mathrm{H}}$, the diffusion of heat in the model as

$\mathcal{D}=\nabla \cdot\left(K_{\mathrm{H}} \frac{\partial b}{\partial z} \hat{k}\right)$.

Due to the non-linear terms in the above, we follow T08 and use the diagnostics from the model to form the vorticity budget. The buoyancy equation has terms

$$
\frac{\partial b}{\partial t}=-\mathbf{u} \cdot \nabla b+\mathcal{D}_{b}=\mathrm{ADV} b+\mathrm{DIA} b
$$

where ADV $b$ and DIA $b$ are diagnostics output by the model. Similarly the momentum equations have diagnostic terms like:

$\frac{\partial u}{\partial t}=\mathrm{ADV} u+\mathrm{COR} u+\operatorname{PRES} u+\mathrm{FRIC} u$.

The vertical velocity in ROMS is a diagnostic variable determined from continuity, so the vorticity equation may be approximated:

$q \approx\left(f+\nabla_{H} \times \mathbf{u}_{h}\right) \frac{\partial b}{\partial z}+\frac{\partial u}{\partial z} \frac{\partial b}{\partial y}-\frac{\partial v}{\partial z} \frac{\partial b}{\partial x}$

Writing the PV equation as components yields:

$\frac{\partial q}{\partial t}=\mathrm{ADV}+\mathrm{FRIC}+\mathrm{DIA}+P_{\mathrm{res}}$ where

$$
\begin{aligned}
& \mathrm{ADV}=\left(f+\frac{\partial v}{\partial x}-\frac{\partial u}{\partial y}\right) \frac{\partial}{\partial z}(\mathrm{ADV} b) \\
& +\frac{\partial b}{\partial z} \frac{\partial}{\partial x}(\mathrm{ADV} v+\mathrm{COR} v) \\
& -\frac{\partial b}{\partial z} \frac{\partial}{\partial y}(\mathrm{ADV} u+\mathrm{COR} u) \\
& +\frac{\partial b}{\partial y} \frac{\partial}{\partial z}(\mathrm{ADV} u+\mathrm{COR} u) \\
& +\frac{\partial u}{\partial z} \frac{\partial}{\partial y}(\mathrm{ADV} b) \\
& -\frac{\partial b}{\partial x} \frac{\partial}{\partial z}(\mathrm{ADV} v+\mathrm{COR} v) \\
& -\frac{\partial v}{\partial z} \frac{\partial}{\partial x}(\mathrm{ADV} b) \\
& \text { FRIC }=\frac{\partial b}{\partial z}\left(\frac{\partial}{\partial x}(\text { FRIC } v)-\frac{\partial}{\partial y}(\text { FRIC } u)-\right) \\
& \left.\frac{\partial b}{\partial y} \frac{\partial}{\partial z}(\text { FRIC } u)-\frac{\partial b}{\partial x} \frac{\partial}{\partial z} \text { (FRIC } v\right) \\
& \mathrm{DIA}=\left(f+\frac{\partial v}{\partial x}-\frac{\partial u}{\partial y}\right) \frac{\partial}{\partial z}(\mathrm{DIA} b) \\
& +\frac{\partial u}{\partial z} \frac{\partial}{\partial y}(\mathrm{DIA} b) \\
& -\frac{\partial v}{\partial z} \frac{\partial}{\partial x}(\mathrm{DIA} b) \\
& P_{\text {res }}=\frac{\partial b}{\partial z}\left(\frac{\partial}{\partial x}(\operatorname{PRES} v)-\frac{\partial}{\partial y}(\operatorname{PRES} u)\right) \\
& +\frac{\partial b}{\partial y} \frac{\partial}{\partial z}(\operatorname{PRES} u)-\frac{\partial b}{\partial x} \frac{\partial}{\partial z}(\operatorname{PRES} v)
\end{aligned}
$$

The last term should be zero because it is the curl of a gradient, so non-zero values represent errors due to the finite difference approximations in the model.

We wish to evaluate the PV equation equation (A8) over a volume $V(t)$ that changes with time and is defined laterally by lateral grid cells in our domain of interest, and vertically by isopycnals. Using Leibniz' theorem

$$
\begin{aligned}
\frac{\mathrm{d}}{\mathrm{d} t} \int_{V(t)} q \mathrm{~d} V= & \int_{V(t)}\left(\mathrm{ADV}+\mathrm{FRIC}+\mathrm{DIA}+P_{\text {res }}\right) \mathrm{d} V \\
& +\int_{A(t)} q \mathbf{u}_{A} \cdot \mathrm{d} \mathbf{A},
\end{aligned}
$$

where $\mathbf{u}_{A}$ is the velocity of the bounding volume and $\mathrm{d} \mathbf{A}$ a bounding area element, positive outwards. The temporally discretized equation is therefore:

$$
\begin{aligned}
\int_{V^{\prime}} q^{\prime} \mathrm{d} V= & \delta t \int_{V} \mathrm{ADV}+\mathrm{FRIC}+\mathrm{DIA}+P_{\text {res }} \mathrm{d} V \\
& +\int_{V^{\prime}-V} q \mathrm{~d} V
\end{aligned}
$$


where $q^{\prime}$ is the vorticity at the new timestep and $V^{\prime}-V$ is the volume that has changed between the time steps, in this case both above and below the initial positions of the isopycnals.

Discretization required care in centering derivatives on the appropriate grid cells, and the diagnostic data output by ROMS was calculated at the midpoint of the snapshot data from the model, so the diagnostics were interpolated to the snapshots. Time derivatives were centered.

In the case where the control volume included landmasked regions, the masked grid cells and those directly adjacent were not included in the calculation.

The results of the budget indicate good agreement between the rate of change of PV observed in the volume, and the terms that drive those changes (Fig. 15). There is a clear tidal signal to the total PV at the cape, with positive PV changes during flood tide, and negative during ebb. All the terms except the DIA and PRES res are large, indicating the importance of friction for producing the PV and advection in moving it away.

\section{Supplementary material related to this article is available online at: http://www.ocean-sci.net/7/487/2011/ os-7-487-2011-supplement.zip.}

Acknowledgements. Thanks to Jim Gower, Stephanie King, and Thomas VanManen at the Institute of Ocean Sciences for providing the imagery in Fig. 1. Emmanuel DiLorenzo supplied code for initializing the simulations that we modified and helped answer some questions about using ROMS. Thanks to Chris Garrett and Eric Kunze for a number of very helpful discussions. W. C. was funded by the BC Ministry of Energy, Mines, and Petroleum Resources, J. M. K. by a Canadian NSERC Discovery Grant.

Edited by: J. M. Huthnance

\section{References}

Afanasyev, Y.: Spontaneous emission of gravity waves by interacting vortex dipoles in a stratified fluid: laboratory experiments, Geophysical \& Astrophysical Fluid Dynamics, 97, 79-95, 2003.

Bruce, J.: Eddies southwest of the Denmark Strait, Deep-Sea Res. Pt. I, 42, 13-17, 1995.

Capet, X., McWilliams, J., Molemaker, M., and Shchepetkin, A.: Mesoscale to submesoscale transition in the California Current System. Part I: Flow structure, eddy flux, and observational tests, J. Phys. Oceanogr., 38, 29-43, 2008.

Cenedese, C. and Whitehead, J.: Eddy shedding from a boundary current around a cape over a sloping bottom, J. Phys. Oceanogr., 30, 1514-1531, 2000.

Cenedese, C., Whitehead, J., Ascarelli, T., and Ohiwa, M.: A dense current flowing down a sloping bottom in a rotating fluid, J. Phys. Oceanogr., 34, 188-203, 2004.

Chapman, D.: Numerical treatment of iron-shelf open boundaries in a barotropic coastal ocean model, J. Phys. Oceanogr., 15, 1060$1075,1985$.
Chelton, D., Deszoeke, R., Schlax, M., El Naggar, K., and Siwertz, N.: Geographical variability of the first baroclinic Rossby radius of deformation, J. Phys. Oceanogr., 28, 433-460, 1998.

Cherniawsky, J., Foreman, M., Crawford, W., and Henry, R.: Ocean tides from TOPEX/Poseidon sea level data, J. Atmos. Ocean. Tech., 18, 649-664, 2001.

Crawford, W.: Physical characteristics of Haida eddies, J. Oceanogr., 58, 703-713, 2002.

Crawford, W., Woodward, M., Foreman, M., and Thomson, R.: Oceanographic features of Hecate Strait and Queen Charlotte Sound in summer, Atmos. Ocean, 33, 639-681, 1995.

Crawford, W., Cherniawsky, J., Foreman, M., and Gower, J.: Formation of the Haida-1998 oceanic eddy, J. Geophys. Res.Oceans, 107, 3069, doi:10.1029/2001JC000876, 2002.

Cummins, P. and Oey, L.: Simulation of barotropic and baroclinic tides off northern British Columbia, J. Phys. Oceanogr., 27, 762781, 1997.

Cushman-Roisin, B., Tang, B., and Chassignet, E.: Westward Motion of Mesoscale Eddies, J. Phys. Oceanogr., 20, 758-768, 1990

D'Asaro, E.: Generation of submesoscale vortices: A new mechanism, J. Geophys. Res, 93, 6685-6693, 1988.

Di Lorenzo, E., Foreman, M., and Crawford, W.: Modelling the generation of Haida Eddies, Deep-Sea Res. Pt. II, 52, 853-873, 2005.

Edwards, K. A., MacCready, P., Moum, J. N., Pawlak, G., Klymak, J. M., and Perlin, A.: Form Drag and Mixing due to Tidal Flow past a Sharp Point, J. Phys. Oceanogr., 34, 1297-1312, 2003.

Flather, R.: A tidal model of the northwest European continental shelf, Mem. Soc. R. Sci. Liege, 10, 141-164, 1976.

Foreman, M., Crawford, W., Cherniawsky, J., Henry, R., and Tarbotton, M.: A high-resolution assimilating tidal model for the northeast Pacific Ocean (Paper 1999JC000122), J. Geophys Res.-Oceans, 105, 28629-28652, 2000.

Foreman, M., Callendar, W., MacFadyen, A., Hickey, B., Thomson, R., and Di Lorenzo, E.: Modeling the generation of the Juan de Fuca Eddy, J. Geophys. Res, 113, C03006, doi:10.1029/2006JC004082, 2008.

Garrett, C.: Flow separation in the ocean, in: Topographic Interactions in the Ocean: Proc.' Aha Huliko'a Workshop, 119-124, 1995.

Geyer, W. R. and Signell, R.: Measurements of Tidal Flow Around a headland With a Shipboard Acoustic Doppler Current Profiler, J. Geophys. Res., 95, 3189-3179, 1990.

Gill, A. E.: Atmosphere-Ocean Dynamics, Academic, San Diego, CA, 1982.

Gower, J. and Tabata, S.: Measurement of eddy motion in the northeast Pacific using the Geosat altimeter, Satellite Remote Sensing of the Oceanic Environment, 375-382, 1993.

Klymak, J. M. and Gregg, M. C.: The Three-dimensional Nature of Flow near a Sill, J. Geophys. Res., 106, 22295-22311, 2001.

Kundu, P. K.: Fluid Mechanics, Academic Press, San Diego, CA, 1990.

Lane-Serff, G. and Baines, P.: Eddy formation by dense flows on slopes in a rotating fluid, J. Fluid Mech., 363, 229-252, 1998.

MacCready, P. and Pawlak, G.: Statified Flow along a Rough Slope: Separation Drag and Wave Drag, J. Phys. Oceanogr., 31, 2824 2839, 2001.

Marshall, J. and Nurser, A.: Fluid dynamics of oceanic thermocline ventilation, J. Phys. Oceanogr., 22, 583-595, 1992. 
McWilliams, J.: Submesoscale, coherent vortices in the ocean, Rev. Geophys., 23, 165-182, 1985.

Melsom, A., Meyers, S., Hurlburt, H., Metzger, J., and O'Brien, J.: ENSO effects on Gulf of Alaska eddies, Earth Interact., 3, 1-30, 1999.

Signell, R. P. and Geyer, W. R.: Transient Eddy Formation Around Headlands, J. Geophys. Res., 96, 2561-2575, 1991.

Song, Y. and Haidvogel, D.: A semi-implicit ocean circulation model using a generalized topography-following coordinate system, J. Comput. Phys., 115, 228-244, 1994.

Sundermeyer, M. and Ledwell, J.: Lateral dispersion over the continental shelf- Analysis of dye release experiments, J. Geophys. Res., 106, 9603-9621, 2001.

Thomas, L., Tandon, A., and Mahadevan, A.: Submesoscale processes and dynamics, in: Ocean modeling in an eddying regime, edited by: Hecht, M. and Hasumi, H., vol. 177 of Geophysical monograph series, American Geophysical Union, Washington DC, 17-38, 2008.
Thomson, R. and Gower, J.: A basin-scale instability event in the Gulf of Alaska, J. Geophys. Res., 103, 3033-3040, 1998.

Thomson, R. and Wilson, R.: Coastal current and mesoscale eddy formation by tidal rectification near an oceanic cape, J. Phys. Oceanogr., 17, 2096-2126, 1987.

Wang, G. and Dewar, W.: Meddy-seamount interactions: Implications for the Mediterranean salt tongue, J. Phys. Oceanogr., 33, 2446-2461, 2003.

Warner, J. C., Sherwood, C. R., Arango, H. G., and Signell, R. P.: Performance of four turbulence closure methods implemented using a generic length scale method, Ocean Model., 8, 81-113, 2004.

Whitney, F. and Robert, M.: Structure of Haida eddies and their transport of nutrient from coastal margins into the NE Pacific Ocean, J. Oceanogr., 58, 715-723, 2002. 